\title{
Calcium Administration on Separation from Cardiopulmonary Bypass: Looking Beyond a Facilitated Weaning!
}

\author{
Rohan Magoon $^{1} \quad$ Neeti Makhija ${ }^{1} \quad$ Surendra Kumar Jangid ${ }^{1}$ \\ ${ }^{1}$ Department of Cardiac Anaesthesia, Cardiothoracic Centre, CNC, \\ All India Institute of Medical Sciences, New Delhi, India \\ Address for correspondence Neeti Makhija, MD, Department of \\ Cardiac Anaesthesia, Cardiothoracic Centre, CNC, All India Institute \\ of Medical Sciences, Room No. 9,7th Floor, Ansari Nagar, New Delhi, \\ 110029, India (e-mail: neetimakhija@hotmail.com).
}

J Card Crit Care TSS 2020;3:53-54

To the Editor,

Weaning from cardiopulmonary bypass (CPB) to a spontaneous performance of the cardiovascular system is essentially a complex process. Effective and safe weaning management strategies continue to be formulated and evaluated to ensure a smooth separation from CPB aimed at optimizing the patient outcomes. A range of pharmacotherapy is often employed during weaning including inotropic and vasopressor infusions to augment myocardial and cardiovascular functioning. In addition, many practitioners administer calcium salts during weaning, albeit the rationale supporting this routine administration has often been debated.

Most of the studies support the premise that a mild hypocalcemia results following CPB. However this degree of hypocalcemia has not been found to remarkably impair the cardiovascular performance. ${ }^{1}$ Literature outlines that supplementing calcium has a positive impact on the postbypass mean arterial pressure and systemic vascular resistance, particularly relevant in context of post-CPB vasoplegia. ${ }^{\text {S Several }}$ authors also propose a concomitantly increased ventricular cardiac index $(\mathrm{Cl})$ with calcium, while some others fail to demonstrate an accentuated $\mathrm{CI}^{2}$ Despite a systolic function augmentation, the negative effects of calcium on diastolic function by causing ventricular stiffness is revealed in literature which raises peculiar concerns in setting of difficult weaning owing to diastolic dysfunction. ${ }^{1}$ With regards to the right ventricle (RV) function, calcium administration is believed to support the RV performance without discernible elevation of pulmonary vascular resistance. ${ }^{3}$

The administration of calcium during weaning is compounded by certain important caveats necessitating attention. First and foremost is the impact of calcium on the myocardium that has suffered an ischemic insult, as calcium overload hypothesis has been centrally implicated in ischemia-reperfusion injury and post-CPB myocardial stunning. ${ }^{1}$ The theory of the "calcium-paradox" as supported by the experimental settings, can further affect the myocardial function adversely. ${ }^{4}$ The other concern regarding calcium administration in

published online

September 12, 2019
DOI https://doi.org/

10.1055/s-0039-1697686 ISSN 2457-0206. scenario of a pressure-overload hypertrophy emanates from the risk of "stone-heart" syndrome. ${ }^{5}$ Moreover, calcium is believed to negatively interact with the concurrent catecholamines by attenuating the response to $\beta$-sympathomimetics. ${ }^{6}$

In addition to the cardiovascular effects, the consequences on the other organs need to be evaluated in a meticulous manner. A significant compromise in the internal mammary and radial artery graft flow begets ventricular supplydemand mismatch primarily accounted by the calcium-induced vascular spasm. ${ }^{7}$ A heightened risk of pancreatic cellular injury limits liberal use of calcium supplementation. ${ }^{8}$ However, these extracardiac effects of calcium merit further focused research. Many researchers argument that appropriate doses can limit the extent of pancreatic insult while promoting the clotting mechanisms aimed at minimizing postoperative bleeding, which is a pertinent issue following congenital cardiac surgery in cyanotics particularly in setting of an increased blood product transfusion requirement. ${ }^{9}$

To conclude, calcium homeostasis in a cardiac surgery contemplated on CPB is complicated with many influencing factors such as hemodilution, acid-base alterations, citrated blood transfusions, albumin concentration, and prime constituents. Calcium administration at weaning is associated with a myriad of cardiac and extracardiac effects. However, several evidence gaps exist in the supplementation of calcium on CPB separation. These include the effect of calcium administration on post-CPB vasoplegia, interaction with calcium-channel sensitizers, and formal assessment of adverse effects such as pancreatic cellular injury, in close conjunction with the patient-specific clinically pertinent long-term outcomes following high-risk cardiac surgery beyond a facilitated weaning from bypass. Bridging these evidence breaches could account for a more scientific, and judicious weaning regime enterprising a safe, optimal, individualized, and effective calcium administration.

\section{Conflicts of Interest}

None.
Copyright $\odot 2020$ Official Publication of The Simulation

Society (TSS), accredited

by International Society of

Cardiovascular Ultrasound (ISCU).
License terms

(영 (1) $\Theta \circledast$ 


\section{References}

1 Lomivorotov VV, Leonova EA, Belletti A, Shmyrev VA, Landoni G. Calcium administration during weaning from cardiopulmonary bypass: a narrative literature review (in press) J Cardiothorac Vasc Anesth 2019 (e-pub ahead of print). doi 10.1053/j. jvca.2019.06.016

2 Royster RL, Butterworth JF IV, Prielipp RC, et al. A randomized, blinded, placebo-controlled evaluation of calcium chloride and epinephrine for inotropic support after emergence from cardiopulmonary bypass. Anesth Analg 1992;74(1):3-13

3 Urban MK, Hines R. The effect of calcium on pulmonary vascular resistance and right ventricular function. J Thorac Cardiovasc Surg 1992;104(2):327-332

4 Oliveira MA, Brandi AC, Dos Santos CA, et al. The calcium paradox-what should we have to fear? Rev Bras Cir Cardiovasc 2014;29(2):249-254
5 Hald M, Hønge J, Dall RP, Larsen SH. Two cases of "stone heart" with fatal outcome. J Thorac Dis 2018;10(1):E74-E76

6 Zaloga GP, Strickland RA, Butterworth JF, IV. Mark LJ, Mills SA, Lake CR. Calcium attenuates epinephrine's beta-adrenergic effects in postoperative heart surgery patients. Circulation 1990;81(1):196-200

7 Janelle GM, Urdaneta F, Martin TD, Lobato EB. Effects of calcium chloride on grafted internal mammary artery flow after cardiopulmonary bypass. J Cardiothorac Vasc Anesth 2000; $14(1): 4-8$

8 Nys M, Venneman I, Deby-Dupont G, et al. Pancreatic cellular injury after cardiac surgery with cardiopulmonary bypass: frequency, time course and risk factors. Shock 2007;27(5):474-481

9 Palta S, Saroa R, Palta A. Overview of the coagulation system. Indian J Anaesth 2014;58(5):515-523 